\title{
Age Management Medicine and Applied Healthspan Engineering: closely connected
}

David $\mathrm{IMB}^{1 *}$

${ }^{1}$ Clinical Nutrition Practitioner, Post-Graduate Program in Health Sciences, Universidade do Sul de Santa Catarina, Av. Pedra Branca, Brazil

Corresponding Author: Isabela M. B. David, MD

Address: Clinical Nutrition Practitioner, Post-Graduate Program in Health Sciences, Universidade do Sul de Santa Catarina, Av. Pedra Branca, 25. Palhoça SC, 88137-270, Brazil; Email: contato.isabeladavid@gmail.com

Received date: 05 January 2020; Accepted date: 30 January 2020; Published date: 06 February 2020

Citation: David IMB. Age Management Medicine and Applied Healthspan Engineering: closely connected. Asp Biomed Clin Case Rep. 2020 Feb 06;3(1):42-43.

Copyright (C) 2020 David IMB. This is an open-access article distributed under the Creative Commons Attribution License, which permits unrestricted use, distribution, and reproduction in any medium provided the original work is properly cited.

\section{Keywords}

Ageing; Applied Healthspan; Medicine

All Age Management Medicine practitioners should read carefully James Larrick and Andrew Mendelsohn's article entitled Applied Healthspan Engineering [1]. The best way to explain briefly what AHE is all about is to include here the abstract of the referred article, published in 2010.

"All organisms have a minimal level of functional reserve required to sustain life that eventually declines to a point incompatible with survival at death. AHE seeks to maintain or restore the optimal functional reserve of critical tissues and organs. Tissue reserve correlates with well being. Diet, physical exercise, and currently available small molecule based therapeutics may attenuate the rate of decline of specific organs or organ systems, but are unlikely to restore lost reserve. Inherent evolutionary-derived limitations in tissue homeostasis and cell maintenance necessitate the development of therapies to enhance regenerative processes and possibly replace whole organs or tissues. AHE supports the study of the cell, tissue, and organ homeostatic mechanisms to derive new regenerative and tissue replacement therapies to extend the period of human health."

When you read "AHE seeks to maintain or restore optimal functional reserve of critical tissues and organs", you must have made a connection with Age Management Medicine once it also aims at health optimization and maintenance. In other words, they both want to help us live better and longer.

Age Management Medicine and Applied Healthspan Engineering have developed themselves because, in the $21^{\text {st }}$ century, we realised that we have already knowledge and technology to maintain health throughout our lives. We don't mean that it is easy and that it is likely to happen to everyone or to most of us at least for the moment - but it is certainly already possible to delay the rate of decline that has always being associated with ageing. For that, we must dedicate ourselves to health optimization and make use of effective tools: diet, exercises, sleep, stress management, toxin reduction, social connections and, surprisingly though it might sound, simplicity [2]. 


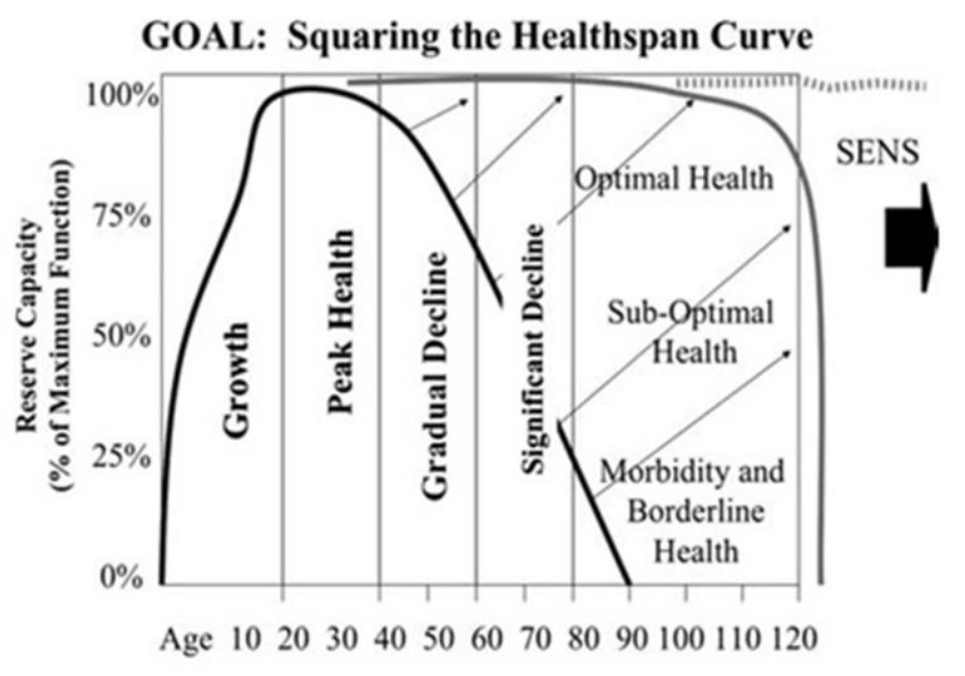

Fig-1: The Healthspan Curve

The minimal goal of Applied Healthspan Engineering (AHE) is to square the healthspan curve. Well-being peaks at the end of the growth phase and then declines. AHE seeks to stabilize well-being, possibly resulting in increased longevity [1] .

Fig-1, taken from Larrick and Mendelsohn's article, shows clearly that the human healthspan begins at conception and continues until death. The first two decades of life are characterized by growth and development. Maximum vitality is obtained in the late teens and twenties, followed by gradual degeneration, accumulating morbidity and eventually death [1].

Considering that accumulation of molecular damage at least partially explains the process of ageing [3,4], Age Management Medicine would also be able to contribute to squaring the healthspan curve, as proposed by AHE. In this case, the control of inflammation, oxidation and glycation biomarkers among others, such as acidification and submethylation ones - should start at "early" age, before the maximum vitality in the late teens and twenties. The idea is to keep them optimal, not only at normal ranges.

Also, both Age Medicine Medicine and Applied Healthspan Engineering accept that one may start working on optimising his/her health at any point in the lifespan curve if the decline has already started.

The main difference between them is that Age Medicine Medicine instructs their practitioners to extend all the available knowledge and treatments directly on to the patients, while AHE is basically related to researchers who work hard on developing new regenerative and tissue replacement therapies "to extend the period of human health" [1].

Last but not least, for all this, we call the $21^{\text {st }}$ century Preventive Medicine the science of maintaining health.

\section{References}

[1] Larrick JW, Mendelsohn A. Applied Healthspan engineering. Rejuvenation Res. 2010 Apr-Jun;13(23):265-8o. [PMID: 20462384]

[2] Website:

http://www.healthoptimizationprogram.com/

[3] Giacomoni PU. Ageing, science and the cosmetics industry. The micro-inflammatory model serves as a basis for developing effective anti-ageing products for the skin. EMBO Rep. 2005 Jul;6 Spec No:S45-48. [PMID: 15995662]

[4] Sergiev PV, Dontsova OA, Berezkin GV. Theories of ageing: an ever-evolving field. Acta Naturae. 2015 JanMar;7(1):9-18. [PMID: 25926998] 